\title{
Biomimetic Synthesis of Hitorins A and B via an Intermolecular Alkoxy Radical-Olefin Coupling Cascade
}

\author{
Xiaohuan Li, Tianran Zhai, Ping He, Zheng Wei, and Zhang Wang* \\ University at Albany, State University of New York, 1400 Washington Avenue, Albany, New York 12222, United States.
}

\section{Supporting Information Placeholder}

\begin{abstract}
A biomimetic synthesis of hitorins A and B was achieved based on our modified biosynthetic proposal. In our synthesis, a radical cascade reaction between an alkoxy radical, generated from a hydroperoxide, and a monoterpene (+)-sabinene renders the tetrahydrofuran ring of hitorins $\mathrm{A}$ and $\mathrm{B}$. In addition, experimental results supported that the oxidative cleavage of the tetrasubstituted olefin in a key intermediate is via a radical oxidation cascade followed by a Grob fragmentation.
\end{abstract}

Nature often uses cascade reactions, optimized over millions of years of evolution, as a strategy for assembly of complex chemical structures. ${ }^{1}$ Uncovering these cascade reactions improves our understanding of both chemical reactivity and biosynthesis of natural products. Organic chemists are also inspired by these cascade reactions and are still learning to apply them in total synthesis in order to achieve synthetic efficiency. ${ }^{2}$ In this work, we employed a radical cascade starting from a rare intermolecular alkoxy radical-olefin coupling reaction in our biomimetic synthesis. ${ }^{3}$
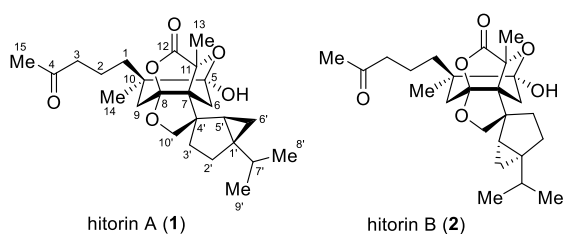

Figure 1. Hitorins A and B.

In October 2016, Kim et al. reported the isolation of two structurally unique $\mathrm{C}_{25}$ terpenoids, hitorins $\mathrm{A}(\mathbf{1})$ and $\mathrm{B}(\mathbf{2})$ from Chloranthus japonicas (Figure 1), ${ }^{4}$ a plant used as a traditional medicine in Japan for the treatment of gastrointestinal disorders. Hitorins A and B contain an unprecedented $6 / 5 / 5 / 5 / 5 / 3$ hexacyclic skeleton with two adjacent quaternary carbons. The isolation team proposed that, biogenetically, hitorins A (1) and B (2) were adducts of two other natural products, atractylenoide III (3) and (+)-sabinene (4). As shown in Scheme 1, olefin isomerization of atractylenoide III furnished compound $\mathbf{5}$, and non-selective epoxidation of (+)-sabinene formed epoxide $\mathbf{6}$ as diastereomers. Then the two compounds 5 and $\mathbf{6}$ coupled to generate adducts 7 and 7'. Nonetheless, the detailed mechanism of this key coupling step with the formation of a tetrahydrofuran ring was not specified. The isolation team believed that the C4'-C7 bond formation was not stereospecific, so both isomers 7 and 7' were concurrently generated. Hitorins A (1) and B (2) are the hemiketals of compounds $\mathbf{8}$ and $\mathbf{8}$ ', respectively, which were proposed to be the respective oxidative cleavage products of compounds 7 and 7'. Again, their proposal did not specify the detailed mechanism of this biological oxidative cleavage of the $\Delta^{4,5}$. tetrasubstituted alkene.

Scheme 1. Biosynthesis of hitorins A and B proposed by Kim et al. ${ }^{4}$
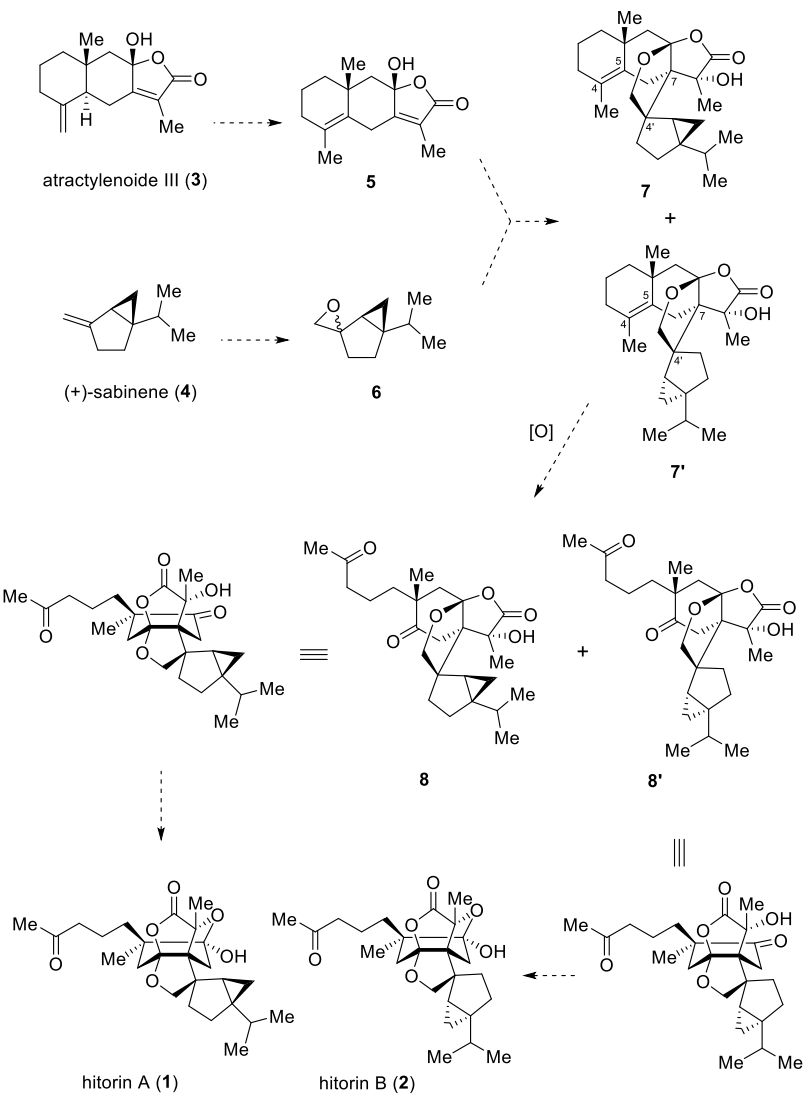

After carefully studying the potential mechanistic details of the formation of compound $\mathbf{7}$ from monomers $\mathbf{5}$ and $\mathbf{6}$, we consider that a modification in the biosynthetic proposal of hitorins is necessary. Simple cationic or anionic mechanisms could not explain this coupling step in Kim's proposal because the regioselectivity and the reactivity of functional groups of $\mathbf{5}$ and $\mathbf{6}$ could not match. Pericyclic mechanisms could not explain the formation of compound 7 from monomers 5 and $\mathbf{6}$ either. As a reasonable alternative, we suggest a radical cascade process for the biosynthesis of 7 . In fact, our modified proposal using a radical cascade would not stop at compound 7 but continue to account for the oxidative cleavage of the $\Delta^{4,5}$-tetrasubstituted alkene, leading to direct precursors of hitorins. 
Scheme 2. Biosynthesis of hitorins A and B proposed in this work (shown for the biosynthesis of hitorin A).

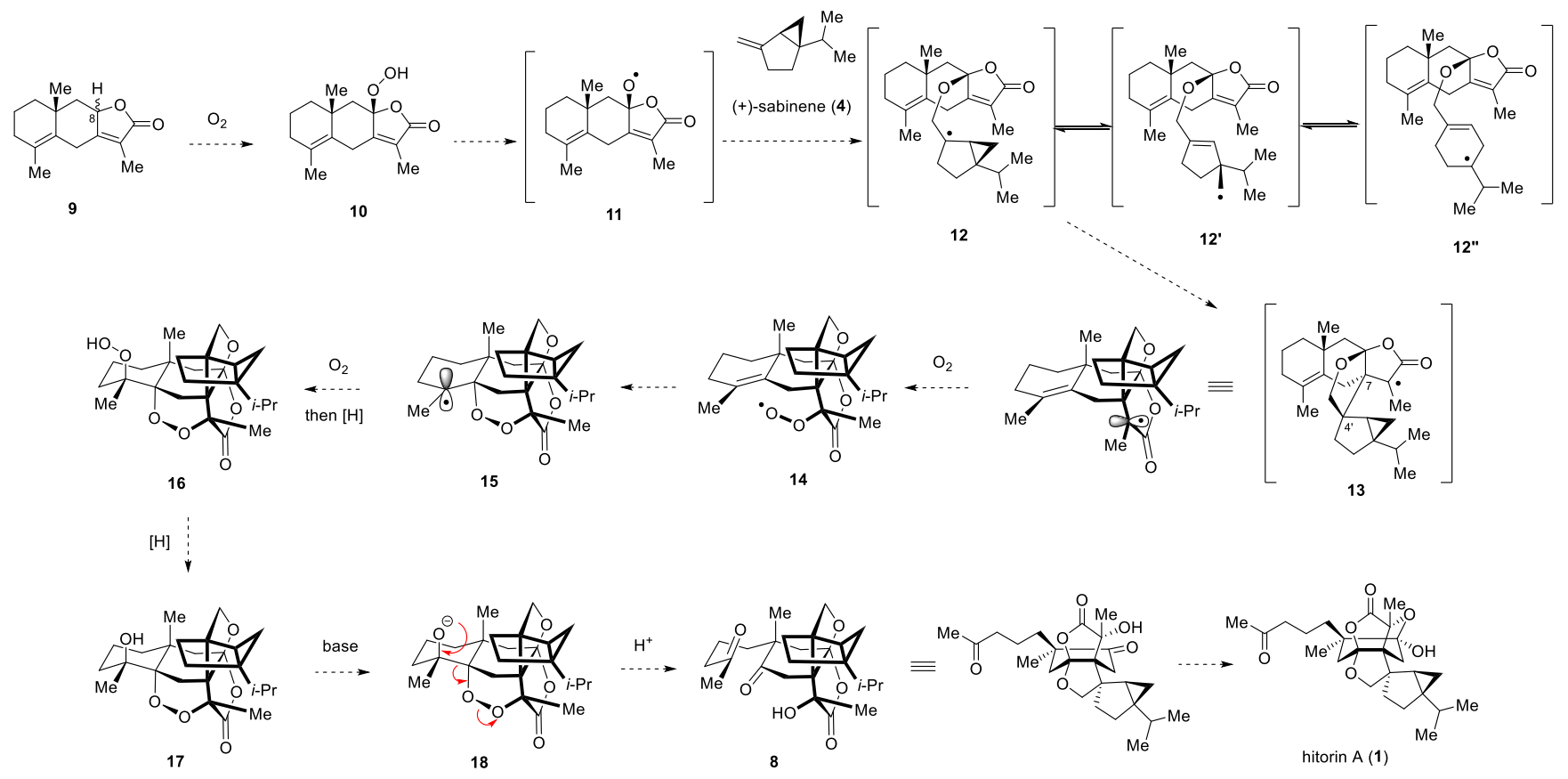

Our new proposal is outlined in Scheme 2, using the biosynthesis of hitorin A (1) as the example. Eudesmane derivative 9 would undergo peroxidation to generate hydroperoxide 10. This peroxidation is a known process in nature, as exemplified by the isolation of some $\gamma$-hydroperoxybutenolide natural products. ${ }^{5}$ Radical peroxidation of butenolide enolates has also been used in total synthesis. ${ }^{6}$ The peroxidation of 2-hydroxyfuran or its anion probably occurs via a radical mechanism. ${ }^{7}$ Then the weak $\mathrm{O}-\mathrm{O}$ single bond of $\mathbf{1 0}$ would be cleaved to form an alkoxy radical 11. ${ }^{8}$ This highly electrophilic oxygen radical could react with (+)-sabinene $\mathbf{4}$ to form a stable tertiary carbon radical 12. ${ }^{9,10}$ The intramolecular version of alkoxy radical-olefin coupling has been proposed for prostacyclin biosynthesis with experimental support by Porter et al. ${ }^{11}$ Radical 12 may be in equilibrium with less strained radicals 12' and 12". ${ }^{12}$ Radical 12 would undergo intramolecular conjugate addition to the electron-deficient butenolide functionality to form the C4'-C7 bond of radical 13, which sets the C4' configuration as $R$. This radical conjugate addition step is not stereospecific, and the C4' $S$ diastereomer of $\mathbf{1 3}$ would eventually lead to the formation of hitorin B (2). We envision that radicals 12' and 12" would not undergo the radical conjugate addition like radical 12 because, if so, it would afford a strained trans-cyclooctene ring. In general, a cyclopropylmethyl radical opens fast $\left(\mathrm{k}: \sim 10^{8} \mathrm{~s}^{-1}\right)$ to form a homoallyl radical, while the reverse reaction, if facilitated by the gem-dimethyl effect, is also fast $\left(\mathrm{k}: \sim 10^{6} \mathrm{~s}^{-1}\right)$. The 5-exo-trig radical cyclization proceeds with a rate constant of $10^{5} \sim 10^{8} \mathrm{~s}^{-1} .{ }^{13}$ In the hitorin biosynthesis, the 5-exo-trig radical cyclization could be the productive pathway under the Curtin-Hammett principle, ${ }^{14}$ leading to radical 13. Radical 13 would then react with oxygen in the air to generate peroxy radicals $\mathbf{1 4}$ and 11-epi-14 (the latter is not shown here), ${ }^{15}$ and the new radical 14 would react with the electron-rich $\mathrm{C}=\mathrm{C}$ bond to form a carbon radical 15. Radical 15 would then react with a second molecule of oxygen to furnish compound $\mathbf{1 6}$ after quenching the peroxy radical intermediate with some reductant. Upon reduction of the hydroperoxide in 16, intermediate $\mathbf{1 7}$ could undergo a Grob fragmentation, ${ }^{16,17}$ furnishing compound $\mathbf{8}$, and hitorin A (1) should form immediately after hemiketal formation. Hitorin B (2) would be produced similarly. Captivated by the intriguing chemistry embedded in the hitorin biosynthesis, we embarked on the biomimetic synthesis of hitorins A and B. Our successful synthesis of these two natural products, shown below, supported our modified proposal.

\section{Scheme 3. Synthesis of hydroperoxide 10.}

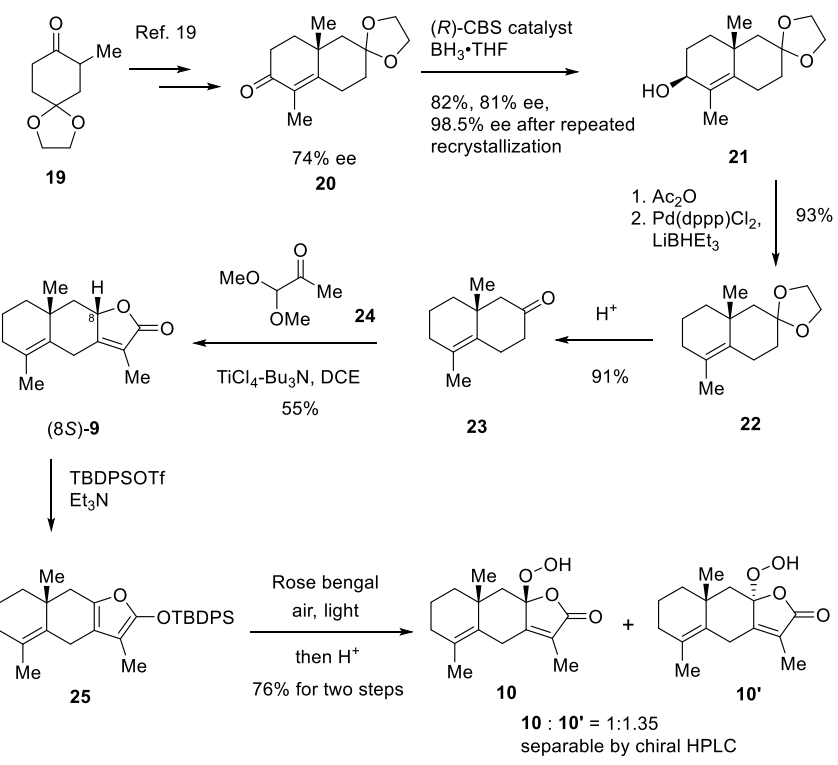

Although structure 9 with an $8 R$ configuration is a known compound, the synthetic route from artemisin is costly..$^{18}$ New chemistry allowed us to prepare hydroperoxide $\mathbf{1 0}$ by a different route. As shown in Scheme 3, enone 20 (74\% ee) was prepared from 19 according to literature. ${ }^{19} \mathrm{CBS}$ reduction of enone 20 provided allylic alcohol 21 with amplified optical purity ( $81 \%$ ee) ${ }^{20}$ Repeated recrystallization of alcohol $\mathbf{2 1}$ from hexanes furnished samples with 98.5\% ee, which were used in subsequent investigations. Alcohol 21 was acetylated, followed by reduction via palladium chemistry to afford compound 22. ${ }^{21}$ After ketal deprotection, a one-pot procedure directly provided the unstable butenolide $(8 S)-\mathbf{9}$ (50\% yield 
Scheme 4. The key alkoxy radical-olefin coupling cascade and a preliminary mechanistic model.

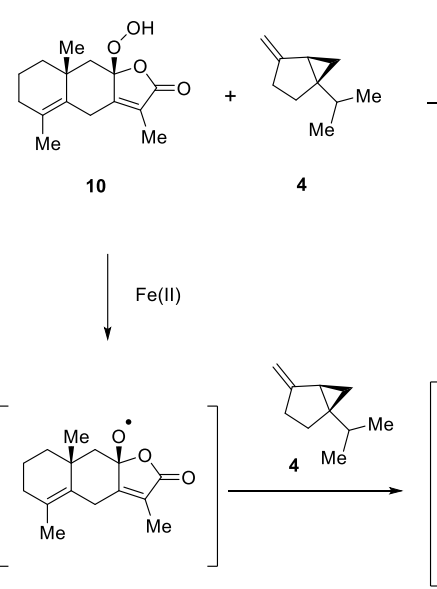

11

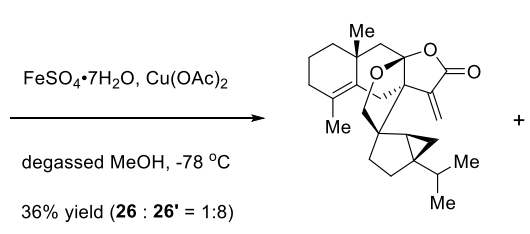

26

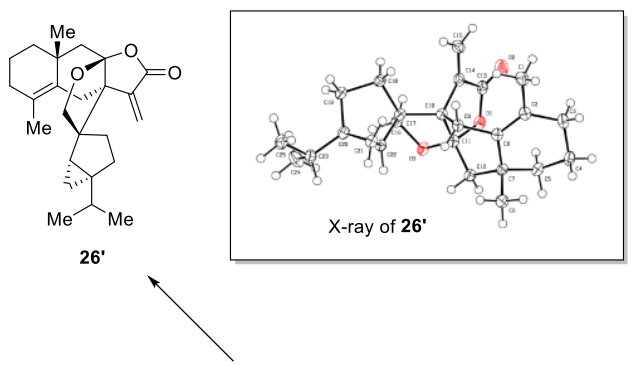

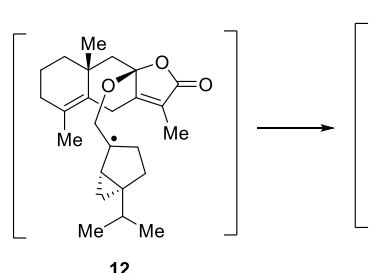

12

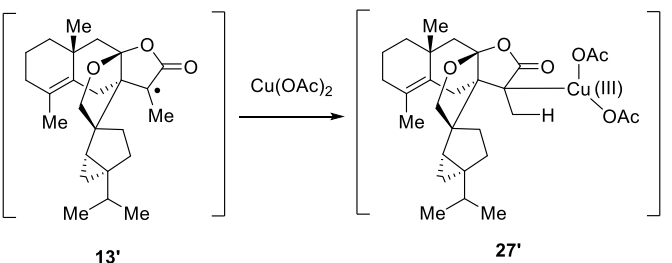

In summary, a radical cascade reaction starting from an alkoxy radical-olefin coupling was proposed for the biosynthesis of hitorins A and B. Our modified proposal led to the first biomimetic synthesis of these two natural products. Our synthesis would disclose nature's expertise to synthesize secondary metabolites using alkoxy radicals. Detailed mechanistic studies and biological evaluations of some advanced intermediates are underway.

\section{Scheme 5. Synthesis of hitorin $B$.} diated by $\mathrm{FeSO}_{4} \cdot 7 \mathrm{H}_{2} \mathrm{O}$ and $\mathrm{Cu}(\mathrm{OAc})_{2}$ in degassed methanol, ${ }^{24}$ to generate lactones $\mathbf{2 6}$ and 26' in a 1:8 ratio in a combined yield of $36 \%$ (Scheme 4 ). ${ }^{25}$ A preliminary mechanistic model of generating 26' is proposed and shown here: $\mathrm{Fe}(\mathrm{II})$ reduces hydroperoxide $\mathbf{1 0}$ to generate alkoxy radical 11, alkoxy radical 11 would then react with (+)-sabinene (4) in a manner similar to that in Scheme 2 to form radical 13'. Formation of compound 26' presumably involves radical oxidation by $\mathrm{Cu}(\mathrm{II})^{26}$ or a Heck-type reaction involving a formal $\beta-\mathrm{H}$ elimination of intermediate $27^{\prime}, 27$ The crystal structure of compound 26' was obtained (CCDC-1870111), confirming the proposed stereochemistry. Compound $\mathbf{2 6}$ should be formed with a similar mechanism. The two compounds $\mathbf{2 6}$ and 26' were separated via HPLC using chiral columns.

The synthesis of compound $\mathbf{2 6}$ and $\mathbf{2 6}$ ' set the stage to test our proposed biosynthetic steps following the generation of radical $\mathbf{1 3}$ (see Scheme 2). As shown in Scheme 5, under hydroperoxidation conditions, ${ }^{28,28 \mathrm{e}}$ radical 13' was formed from pure 26' via hydrogen atom transfer. ${ }^{29}$ Radical 13' then underwent our proposed radical cascade reaction involving $\mathrm{O}_{2}$, rendering a putative hydroperoxide mixture 28' as epimers at C4, together with other unknown compounds. After selective reduction of the hydroperoxide of compound 28' to alcohol by polymer-bound $\mathrm{PPh}_{3}$ (finished in about one hour as shown in mass spectrometry), ${ }^{28,30}$ continued stirring of the reaction mixture for a month led to the completion of the Grob fragmentation of the putative peroxide $29,{ }^{16,17}$ leading to hitorin B (2) in $26 \%$ yield from compound $\mathbf{2 6}{ }^{\prime}{ }^{31}$ The ${ }^{1} \mathrm{H}-\mathrm{NMR}$ spectrum of hitorin B (2) matched the reported data, while we found its ${ }^{13} \mathrm{C}$ NMR spectrum was concentration-dependent, ${ }^{32,33}$ and the spectrum of a concentrated synthetic sample matched the reported data. Hitorin A (1) was also prepared in a similar fashion in $18 \%$ yield from pure compound $\mathbf{2 6}$.
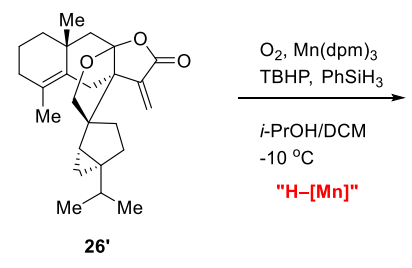

H-[Mn]"
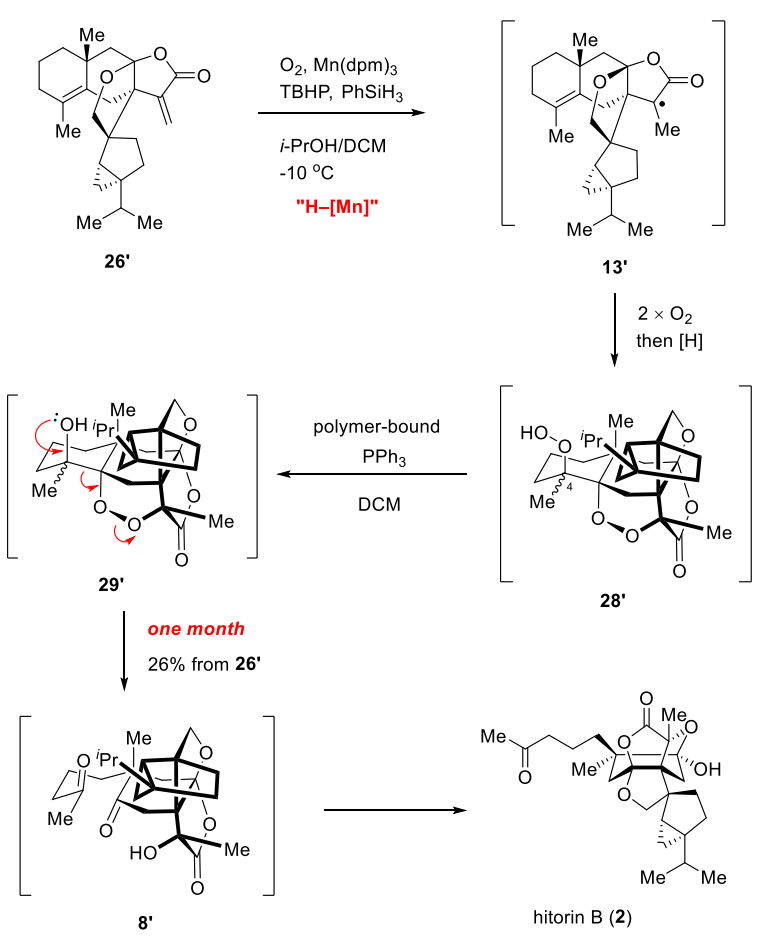

\section{ASSOCIATED CONTENT}

\section{Supporting Information}

Detailed experimental procedures and characterizations of new compounds.

\section{AUTHOR INFORMATION}

Corresponding Author

zwang9@albany.edu 


\section{Notes}

The authors declare no competing financial interests.

\section{ACKNOWLEDGMENT}

Funding from NIH (1R15GM134479-01) and start-up funds from SUNY-Albany are greatly acknowledged. X. Li, T. Zhai, P. He, and Z. Wang thank NSF for NMR and mass spectrometers (1726724 and 1429329, respectively). Z. Wei thanks National Science Foundation (1337594) for the X-ray diffractometer. We sincerely appreciate the help from Lotus Separations, LLC. Prof. Eric Block (SUNY-Albany) is thanked for stimulating discussions. Dr. Ying $\mathrm{Wu}$ is acknowledged for helping preparation of this manuscript. This work is dedicated to Prof. Zhen Yang on the occasion of his $60^{\text {th }}$ birthday.

\section{REFERENCES}

(1) (a) Walsh, C. T.; Moore, B. S. Enzymatic Cascade Reactions in Biosynthesis. Angew. Chem. Int. Ed. 2018, Accepted Article. DOI: 10.1002/anie.201807844. (b) Ueberbacher, B. T.; Hall, M.; Faber, K. Electrophilic and Nucleophilic Enzymatic Cascade Reactions in Biosynthesis. Nat. Prod. Rep. 2012, 29, 337.

(2) (a) Poupon, E.; Nay, B.; Editors. Biomimetic Organic Synthesis, Volume 1: Alkaloids.; Wiley-VCH Verlag GmbH \& Co. KGaA, 2011. (b) Poupon, E.; Nay, B.; Editors. Biomimetic Organic Synthesis, Volume 2: Terpenoids, Polyketides, Polyphenols, Frontiers in Biomimetic Chemistry.; Wiley-VCH Verlag GmbH \& Co. KGaA, 2011. (c) Yoder, R. A. \& Johnston, J. N. A Case Study in Biomimetic Total Synthesis: Polyolefin Carbocyclizations to Terpenes and Steroids. Chem. Rev. 2005, 105, 4730. (d) de la Torre, M. C.; Sierra, M. A. Comments on Recent Achievements in Biomimetic Organic Synthesis. Angew. Chem. Int. Ed. 2004, 43, 160.

(3) For recent reviews of radical chemistry in total synthesis, see: (a) Smith, J. M.; Harwood, S. J.; Baran, P. S. Radical Retrosynthesis. Acc. Chem. Res. 2018, 51, 1807. (b) Hung, K.; Hu, X.; Maimone, T. J. Total Synthesis of Complex Terpenoids Employing Radical Cascade Processes. Nat. Prod. Rep. 2018, 35, 174. (c) Romero, K. J.; Galliher, M. S.; Pratt, D. A.; Stephenson, C. R. J. Radicals in Natural Product Synthesis. Chem. Soc. Rev. 2018, 47, 7851. (d) Pitre, S. P.; Weires, N. A.; Overman, L. E. Forging $\mathrm{C}\left(\mathrm{sp}^{3}\right)-\mathrm{C}\left(\mathrm{sp}^{3}\right)$ Bonds with Carbon-Centered Radicals in the Synthesis of Complex Molecules. J. Am. Chem. Soc. 2018, ASAP, DOI 10.1021/jacs.8b11790. (e) Inoue, M. Evolution of Radical-Based Convergent Strategies for Total Syntheses of Densely Oxygenated Natural Products. Acc. Chem. Res. 2017, 50, 460.

(4) Kim, S.-Y.; Nagashima, H.; Tanaka, N.; Kashiwada, Y.; Kobayashi, J.; Kojoma, M. Hitorins A and B, Hexacyclic $\mathrm{C}_{25}$ Terpenoids from Chloranthus japonicas. Org. Lett. 2016, 18, 5420.

(5) Zhang, Q. F.; Luo, S. D; Wang, H. Y. Two New Sesquiterpenes from Atractylodes macrocephala. Chin. Chem. Lett. 1998, 9, 1097.

(6) (a) Liu, L.-Z.; Han, J.-C.; Yue, G.-Z.; Li, C.-C.; Yang, Z. Asymmetric Total Synthesis of Caribenol A. J. Am. Chem. Soc. 2010, 132, 13608. (b) Han, J.-C.; Liu, L.-Z.; Chang, Y.-Y.; Yue, G.-Z.; Guo, J.; Zhou, L.-Y.; Li, C.-C.; Yang, Z. Asymmetric Total Synthesis of Caribenol A via an Intramolecular Diels-Alder Reaction. J. Org. Chem. 2013, 78, 5492. (c) Boukouvalas, J.; Jean, M.-A. Streamlined Biomimetic Synthesis of Paracaseolide A via Aerobic Oxidation of a 2-Silyloxyfuran. Tetrahedron Lett. 2014 55, 4248. For selected applications of $\mathrm{O}_{2}$ peroxidation in total synthesis, see: (d) Chu-Moyer, M. Y.; Danishefsky, S. J. A Remarkable Cyclopropanation: The Total Synthesis of Myrocin C. J. Am. Chem. Soc. 1992, 114, 8333. (e) Chu-Moyer, M. Y.; Danishefsky, S. J.; Schulte, G. K. Total Synthesis of ( \pm )-Myrocin C. J. Am. Chem. Soc. 1994, 116, 11213. (f) Charest, M. G.; Lerner, C. D.; Brubaker, J. D.; Siegel, D. R.; Myers, A. G. A Convergent Enantioselective Route to Structurally Diverse 6-Deoxytetracycline Antibiotics. Science 2005, 308, 395. (g) Charest, M. G.; Siegel, D. R.; Myers, A. G. Synthesis of (-)-Tetracycline. J. Am. Chem. Soc. 2005, 127, 8292. (h) Schuppe, A. W.; Newhouse, T. R. Assembly of the Limonoid Architecture by a Divergent Approach: Total Synthesis of $( \pm)$-Andirolide N via $( \pm)$ 8 $\alpha$-Hydroxycarapin. J. Am. Chem. Soc. 2017, 139, 631.

(7) (a) Najjar, F.; André-Barrès, C.; Lauricella, R.; Gorrichon, L.; Tuccio, B. EPR/Spin Trapping Study of the Spontaneous Addition of Dioxygen on a Dienol. Tetrahedron Lett. 2005, 46, 2117. (b) Gersmann, H. R.; Bickel, A. F. Autoxidation of Ketones and Esters in Basic Solution. J. Chem. Soc., (B) 1971, 2230. (c) Iio, H.; Nagaoka, H.; Kishi, Y. A Model Study for the
Biomimetic-Type Synthesis of Rifamycin S. Tetrahedron Lett. 1981, 22, 2451.

(8) Gray, P.; Williams, A. The Thermochemistry and Reactivity of Alkoxyl Radicals. Chem. Rev. 1959, 59, 239.

(9) (a) Farmer, E. H.; Moore, C. G. Radical Mechanisms in Saturated and Olefinic Systems. I. Liquid-Phase Reaction of the tert-Butoxy Radical with Olefins and with Cyclohexane. J. Chem. Soc. 1951, 131. (b) Kempter, I.; Groß, A.; Hartung, J. Alkoxyl Radical Addition to Acceptor-Substituted Carbon-Carbon Double Bonds. Tetrahedron 2012, 68, 10378. (c) Kharasch, M. S.; Arimoto, F. S.; Nudenberg, W. The Chemistry of Hydroperoxides. X. The Addition of Free Alkoxy Radicals to Conjugated Systems. J. Org. Chem. 1951, 16, 1556.

(10) The resonance structure 11' may explain its stability, leading to selective intermolecular addition to olefins rather than intramolecular pathways of $1,5-\mathrm{H}$ abstraction or $\beta$-fragmentation. The conformation of $\mathbf{1 1}$ may also play a role in its reaction pattern and the probability of $1,5-\mathrm{H}$ abstraction could be reduced.

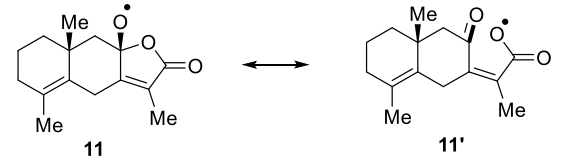

(11) (a) Smith, W. L.; Urade, Y.; Jakobsson, P.-J. Enzymes of the Cyclooxygenase Pathways of Prostanoid Biosynthesis. Chem. Rev. 2011, 111, 5821. (b) Milne, G. L.; Yin, H.; Hardy, K. D.; Davies, S. S.; Roberts, L. J. Isoprostane Generation and Function. Chem. Rev. 2011, 111, 5973. (c) Turner, J. A.; Herz, W. Iron(II)-Induced Decomposition of Epidioxides. A Chemical Model for Prostaglandin E, Prostacyclin and Thromboxane Biosynthesis. Experientia 1977, 33, 1133. (d) Porter, N. A.; Mebane, R. C. An Electron Transfer Model for PGI Biosynthesis. Tetrahedron Lett. 1982, 23, 2289. (e) Yin, H.; Xu, L.; Porter, N. A. Free Radical Lipid Peroxidation: Mechanisms and Analysis. Chem. Rev. 2011, 111, 5944. (f) Pratt, D. A.; Tallman, K. A.; Porter, N. A. Free Radical Oxidation of Polyunsaturated Lipids: New Mechanistic Insights and the Development of Peroxyl Radical Clocks. Acc. Chem. Res. 2011, 44, 458. (g) Porter, N. A. A Perspective on Free Radical Autoxidation: The Physical Organic Chemistry of Polyunsaturated Fatty Acid and Sterol Peroxidation. J. Org. Chem. 2013, 78, 3511. (h) Zielinski, Z. A. M.; Pratt, D. A. Lipid Peroxidation: Kinetics, Mechanisms, and Products. J. Org. Chem. 2017, 82, 2817.

(12) The C5'-C6' single bond is believed to open fast due to better overlap with the $p$-orbital on $\mathrm{C}^{\prime}$ '. For a close example, see: (a) Batey, R. A.; Grice, P.; Harling, J. D.; Motherwell, W. B.; Rzepa, H. S. Origins of the Regioselectivity of Cyclopropylcarbinyl Ring Opening Reactions in Bicyclo [n.1.0] Systems. J. Chem. Soc., Chem. Commun., 1992, 942. For selected examples of using cis-trans isomerization of cyclopropanes to probe radical mechanisms, see: (b) Benkovics, T.; Du, J.; Guzei, I. A.; Yoon, T. P. Anionic Halocuprate(II) Complexes as Catalysts for the Oxaziridine-Mediated Aminohydroxylation of Olefins. J. Org. Chem. 2009, 74, 5545. (c) Van Humbeck, J. F.; Simonovich, S. P.; Knowles, R. R.; MacMillan, D. W. C. Concerning the Mechanism of the $\mathrm{FeCl}_{3}$-Catalyzed $\alpha$-Oxyamination of Aldehydes: Evidence for a Non-SOMO Activation Pathway. J. Am. Chem. Soc. 2010, 132, 10012. (d) Spence, E. L.; Langley, G. J.; Bugg, T. D. H. Cis-trans Isomerization of a Cyclopropyl Radical Trap Catalyzed by Extradiol Catechol Dioxygenases: Evidence for a Semiquinone Intermediate. $J$. Am. Chem. Soc. 1996, 118, 8336.

(13) (a) Griller, D.; Ingold, K. U. Free-Radical Clocks. Acc. Chem. Res. 1980, 13, 317. (b) Newcomb, M. Competition Methods and Scales for Alkyl Radical Reaction Kinetics. Tetrahedron 1993, 49, 1151.

(14) Seeman, J. I. Effect of Conformational Change on Reactivity in Organic Chemistry. Evaluations, Applications, and Extensions of CurtinHammett/Winstein-Holness Kinetics. Chem. Rev. 1983, 83, 83.

(15) (a) Kihara, N.; Ollivier, C.; Renaud, P. Efficient Radical Oxygenation of $\alpha$-Iodocarboxylic Acid Derivatives. Org. Lett. 1999, 1, 1419. (b) Denissova, I.; Maretti, L.; Wilkes, B. C.; Scaiano, J. C.; Guindon, Y. Raising the Ceiling of Diastereoselectivity in Hydrogen Transfer on Acyclic Radicals. J. Org. Chem. 2009, 74, 2438.

(16) Prantz, K.; Mulzer, J. Synthetic Applications of the Carbonyl Generating Grob Fragmentation. Chem. Rev. 2010, 110, 3741.

(17) (a) Richardson, W. H.; Heeson, T. C. The Base-Catalyzed Fragmentation of 2-tert-Butylperoxy-2-methyl-1-propanol. J. Org. Chem. 1972, 37, 3416. (b) Gu, X.; Zhang, W.; Salomon, R. G. Fragmentation of $\beta$-Hydroxy Hydroperoxides. J. Org. Chem. 2012, 77, 1554.

(18) (a) Marco, J. A.; Arno, M.; Carda, M. Synthesis of Yomogin, 1Deoxyivangustin, and 1-Deoxy-8-epiivangustin. Can. J. Chem. 1987, 65, 630. (b) Arno, M.; Carda, M.; Alberto Marco, J.; Seoane, E. Transformation 
of Artemisin into Yomogin and 1-Deoxyivangustin. Chem. Lett. 1984, 13, 1021.

(19) Tenius, B. S. M.; Schroeder, E. K. A Convenient Synthesis of Chiral, Non-Racemic [4aS,8aR]-5,5,8a-Trimethyloctahydro-2,2-(1,3-dioxolane)-naphthalene. Synth. Commun. 2000, 30, 1371.

(20) (a) Corey, E. J.; Helal, C. J. Reduction of Carbonyl Compounds with Chiral Oxazaborolidine Catalysts: A New Paradigm for Enantioselective Catalysis and a Powerful New Synthetic Method. Angew. Chem. Int. Ed. 1998, 37, 1986. (b) Zhao, X.; Li, W.; Wang, J.; Ma, D. Convergent Route to ent-Kaurane Diterpenoids: Total Synthesis of Lungshengenin D and $1 \alpha, 6 \alpha$-Diacetoxy-ent-kaura-9(11),16-dien-12,15-dione. J. Am. Chem. Soc. 2017, 139, 2932.

(21) Ito, F.; Ohbatake, Y.; Aoyama, S.; Ikeda, T.; Arima, S.; Yamada, Y.; Ikeda, H.; Nagamitsu, T. Total Synthesis of (+)-Clavulatriene A. Synthesis 2015, 47, 1348.

(22) (a) Ramesh, S.; Mehta, G. A Total Synthesis of Sarcandralactone A: A General, Concise, RCM Enabled Approach to Lindenanolide Sesquiterpenoids. Tetrahedron Lett. 2015, 56, 3941. (b) Tanabe, Y.; Mitarai, K.; Higashi, T.; Misaki, T.; Nishii, Y. Efficient One-Step Synthesis of Trialkylsubstituted 2(5H)-Furanones Utilizing Direct Ti-Crossed Aldol Condensation and Its Application to the Straightforward Synthesis of $(R)$-Mintlactone and $(R)$-Menthofuran. Chem. Commun. 2002, 2542.

(23) (a) Wasserman, H. H.; Ives, J. L. Singlet Oxygen in Organic Synthesis. Tetrahedron 1981, 37, 1825. (b) Leach, A. G.; Houk, K. N. DielsAlder and Ene Reactions of Singlet Oxygen, Nitroso Compounds and Triazolinediones: Transition States and Mechanisms from Contemporary Theory. Chem. Commun. 2002, 1243.

(24) (a) Čeković, Ž. \& Green, M. M. Formation of Remote Double Bonds by Ferrous Sulfate-Cupric Acetate Promoted Decomposition of Alkyl Hydroperoxides. J. Am. Chem. Soc. 1974, 96, 2999. (b) Schreiber, S. L. Fragmentation Reactions of $\alpha$-Alkoxy Hydroperoxides and Application to the Synthesis of the Macrolide ( \pm )-Recifeiolide. J. Am. Chem. Soc. 1980, 102,6163

(25) A by-product, 11,13-dihydro-26, was also isolated in about $28 \%$ yield, probably as a mixture of stereoisomers. We were unable to isolate the major component in pure form so the stereochemistry of C4' and C11 is unassigned. A mechanistic model for its generation is proposed below.
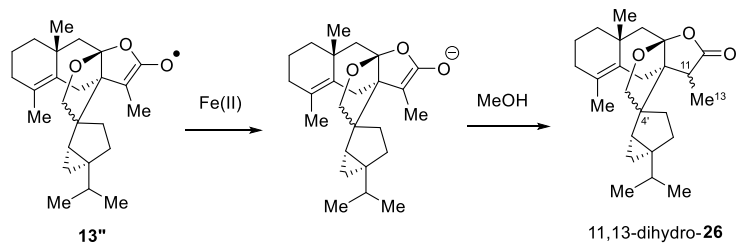

(26) Kochi, J. K.; Bemis, A.; Jenkins, C. L. Mechanism of Electron Transfer Oxidation of Alkyl Radicals by Copper(II) Complexes. J. Am. Chem. Soc. 1968, 90, 4616.

(27) (a) Peng, Y.; Chen, J.; Ding, J.; Liu, M.; Gao, W.; Wu, H. LigandFree Copper-Catalyzed Arylation of Olefins by the Mizoroki-Heck Reaction. Synthesis 2011, 213. (b) Li, J.-H.; Wang, D.-P.; Xie, Y.-X. CuI/Dabco as a Highly Active Catalytic System for the Heck-Type Reaction. Tetrahedron Lett. 2005, 46, 4941.

(28) (a) Isayama, S. An Efficient Method for the Direct Peroxygenation of Various Olefinic Compounds with Molecular Oxygen and Triethylsilane Catalyzed by a Cobalt(II) Complex. Bull. Chem. Soc. Jpn. 1990, 63, 1305. (b) Satoshi, I.; Koji, K.; Shigeru, I.; Mukaiyama, T. A New and Facile Method for the Direct Preparation of $\alpha$-Hydroxycarboxylic Acid Esters from $\alpha, \beta$-Unsaturated Carboxylic Acid Esters with Molecular Oxygen and Phenylsilane Catalyzed by Bis(dipivaloylmethanato)manganese(II) Complex. Chem. Lett. 1990, 19, 1869. (c) Magnus, P.; Payne, A. H.; Waring, M. J.; Scott, D. A.; Lynch, V. Conversion of $\alpha, \beta$-Unsaturated Ketones into $\alpha$ Hydroxy Ketones Using an $\mathrm{Mn}^{\mathrm{III}}$ Catalyst, Phenylsilane and Dioxygen: Acceleration of Conjugate Hydride Reduction by Dioxygen. Tetrahedron Lett. 2000, 41, 9725. (d) Hu, X.; Maimone, T. J. Four-Step Synthesis of the Antimalarial Cardamom Peroxide via an Oxygen Stitching Strategy. J. Am. Chem. Soc. 2014, 136, 5287. (e) Hu, X.; Lim, P.; Fairhurst, R. M.; Maimone, T. J. Synthesis and Study of the Antimalarial Cardamom Peroxide. Tetrahedron 2018, 74, 3358. (f) Szpilman, A. M.; Korshin, E. E.; Rozenberg, H.; Bachi, M. D. Total Syntheses of Yingzhaosu A and of Its $\mathrm{C}(14)$-Epimer Including the First Evaluation of Their Antimalarial and $\mathrm{Cy}$ totoxic Activities. J. Org. Chem. 2005, 70, 3618. (g) Li, Q.; Zhao, K.; Peuronen, A.; Rissanen, K.; Enders, D.; Tang, Y. Enantioselective Total Syntheses of (+)-Hippolachnin A, (+)-Gracilioether A, (-)-Gracilioether E, and (-)-Gracilioether F. J. Am. Chem. Soc. 2018, 140, 1937.

(29) (a) Crossley, S. W. M.; Obradors, C.; Martinez, R. M.; Shenvi, R. A. Mn-, Fe-, and Co-Catalyzed Radical Hydrofunctionalizations of Olefins. Chem. Rev. 2016, 116, 8912. (b) Smith, D. M.; Pulling, M. E.; Norton, J. R. Tin-Free and Catalytic Radical Cyclizations. J. Am. Chem. Soc. 2007, 129, 770. (c) Ishikawa, H.; Colby, D. A.; Seto, S.; Va, P.; Tam, A.; Kakei, H.; Rayl, T. J.; Hwang, I.; Boger, D. L. Total Synthesis of Vinblastine, Vincristine, Related Natural Products, and Key Structural Analogues. J. Am. Chem. Soc. 2009, 131, 4904. (d) Iwasaki, K.; Wan, K. K.; Oppedisano, A.; Crossley, S. W. M.; Shenvi, R. A. Simple, Chemoselective Hydrogenation with Thermodynamic Stereocontrol. J. Am. Chem. Soc. 2014, 136 (4), 1300. (e) King, S. M.; Ma, X.; Herzon, S. B. A Method for the Selective Hydrogenation of Alkenyl Halides to Alkyl Halides. J. Am. Chem. Soc. 2014, 136, 6884. (f) Waser, J.; Gaspar, B.; Nambu, H.; Carreira, E. M. Hydrazines and Azides via the Metal-Catalyzed Hydrohydrazination and Hydroazidation of Olefins. J. Am. Chem. Soc. 2006, 128, 11693.

(30) Adam, W.; Balci, M.; Kilic, H. 2,3-Dioxabicyclo[2.2.2]oct-7-en-5one: Synthesis and Reactions of the Keto Endoperoxide of Phenol. J. Org. Chem. 2000, 65, 5926.

(31) A by-product, 11-epi-7', was also isolated from this reaction mixture in $14 \%$ yield. At least two TLC spots were able to fragment to form hitorin B. The smaller spot fragmented very quickly, usually within hours, but the larger spot, which was a mixture with other compounds, took one month to secure complete fragmentation. So here structures $\mathbf{2 8}^{\prime}$ ' and $\mathbf{2 9}^{\prime}$ 'are proposed to be epimers at $\mathrm{C} 4$.

(32) Johnson, N. O.; Light, T. P.; MacDonald, G.; Zhang, Y. AnionCaffeine Interactions Studied by ${ }^{13} \mathrm{C}$ and ${ }^{1} \mathrm{H}$ NMR and ATR-FTIR Spectroscopy. J. Phys. Chem. B 2017, 121, 1649.

(33) All the ${ }^{13} \mathrm{C}$ NMR spectra of hitorin $\mathrm{B}(2)$ and both the ${ }^{1} \mathrm{H}$ and ${ }^{13} \mathrm{C}$ NMR spectra of hitorin A (1) were recorded using a coaxial insert with the sample solution inside and an outer tube containing only $\mathrm{CDCl}_{3}$ (to assist locking). All other NMR spectra were recorded using regular 5-mm NMR tubes. 

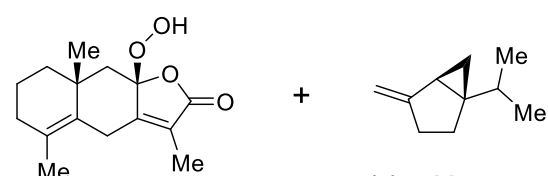

(+)-sabinene

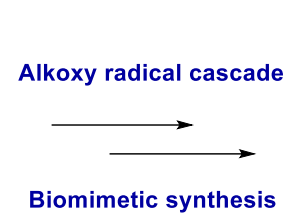

Biomimetic synthesis

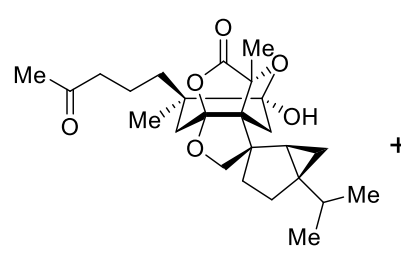

hitorin A

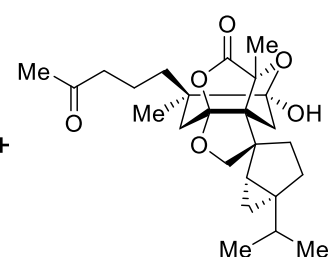

hitorin B 